Borneo Journal of Science \& Technology, Volume (2), Issue (2), Pages: 11-18

DOI: http://doi.org/10.3570/bjost.2020.2.2-03

e-ISSN: 2672-7439

(C) 2018, UCTS Publisher.

Submitted: $31^{\text {th }}$ January 2020 Accepted: $02^{\text {nd }}$ April 202

Published: $31^{\text {th }}$ July 2020

\title{
Performance of Microwave Pre-Treated Elaeis guineensis Fronds Composite Board with Different Selection of Particle Sizes
}

\author{
*Ellisha Iling, Dayang Siti Hazimmah Ali, and Mohd Shahril Osman \\ School of Engineering and Technology, University College of Technology Sarawak (UCTS), \\ 96000 Sibu, Sarawak, Malaysia
}

\begin{abstract}
The size and shape of particles have a significant role in affecting the performance of composite boards. Selection of raw material particle sizes usually contributes to the quality of inter-bonding between particles. This paper focused on the effect of different particle sizes of Elaeis guineensis fronds on the microwave pre-treated $E$. guineensis fronds composite board. Dried fronds were crushed into smaller particles by using a crusher machine. Sieved E. guineensis frond particles that retained on the $0.60 \mathrm{~mm}$ and $1.18 \mathrm{~mm}$ sieve mesh, respectively were selected for composite boards' fabrication. Each board is designed to have a targeted density of $0.8 \mathrm{~g} / \mathrm{cm}^{3}$. The 20 $\mathrm{cm} \times 20 \mathrm{~cm} \times 0.50 \mathrm{~cm}$ composite boards were manufactured under hot press temperatures of $160{ }^{\circ} \mathrm{C}$ at $7 \mathrm{MPa}$. The physical and mechanical properties of $E$. guineensis fronds composite boards were tested according to the Japanese Industrial Standard (JIS A5908:2003). The overall mechanical properties of composite board met the requirement of JIS A5908:2003. E. guineensis fronds composite boards fabricated with $0.60 \mathrm{~mm}$ particle size shown to have better thickness swelling (TS) and internal bonding (IB) strength with value of $29.02 \%$ and $6.23 \mathrm{~N} / \mathrm{mm}^{2}$, respectively compared to $1.18 \mathrm{~mm}$ particle sized composite board. Whereas, better performance of water absorption (WA) and modulus of rupture (MOR) with recorded results of $131.04 \%$ and $22.37 \mathrm{~N} / \mathrm{mm}^{2}$, respectively were found in $E$. guineensis fronds composite boards fabricated from $1.18 \mathrm{~mm}$ particle size. The morphology images by scanning electron microscopy (SEM) revealed that the interlocking and arrangement between particles is closely related to the size of particles.
\end{abstract}

Keywords: Composite Boards, Microwave Pre-Treated, Particle Sizes, Physical, Mechanical.

\section{INTRODUCTION}

Nowadays, the demands of wood-based products are increased significantly. The shortage of wood supply from timbers had encouraged the use of non- woody plants such as kenaf, oil palm residues or bamboo as alternative materials in composite industry [1],[2],[3]. Among the natural resources, oil palm (Elaeis guineensis) fronds are one of less utilized material despite having abundance supply throughout the year.

In a yearly basis, around 44 million tonnes of dry E. guineensis fronds are generated upon harvesting of oil palm fruits which is amounted to $51 \%$ of overall oil palm residue per annum [4],[5]. By the continuous increasing of plantation area, it is expected that the number of $E$. guineensis fronds residue will increase as the average rate of collected E. guineensis fronds during yearly pruning and replanting activities are 10.4 tonnes per hectare [6]. Therefore, the availability of E. guineensis fronds throughout the year and its reasonable cost makes it suitable to be utilized as a raw material for various value-added products [7].

Having hemicellulose content of 1.5 to 3 times more than typical hardwood species, E. guineensis fronds show the same tendency to be used as raw material in composite board making $[8,9]$.

A material formed through the combination of two or more micro- or macro-components having a different structure and chemical composition is called as composite. The important of the composite material is the possessing properties of the end product are superior to the properties of the individual component [10].

Microwave pre-treatment is known as the simplest physical pre-treatment method to improve the bondin

11

Corresponding Author: Ellisha Iling, School of Engineering and Technology, University College of Technology Sarawak (UCTS),

E-mail: ellishailing@student.ucts.edu.my 


\section{Performance of Microwave Pre-Treated Elaeis guineensis Fronds Composite Board with Different Selection of Particle Sizes}

properties of natural fibers [11]. This process does not require high energy consumption and usage of any solvents or auxiliary chemicals. According to Tajuddin, Ahmad [12], the performance of fabricated boards improved after underwent microwave pre-treatment before being consolidated via hot press machine.

In manufacturing of composite board, the size and shape of particles have a significant role in affecting the physical and mechanical properties of composite boards. Selection of raw material particle sizes usually contributes to the quality of inter-bonding between particles.

Hashim et al. [13] and Chiang et al. [14] discovered that coarser particles can cause more overlapping areas and produce larger voids. The presence of vacancy deficiency in composite board tends to cause premature failure because the incompact structure is not strong enough to withstand the typical external force applied.

The purpose of this research was to evaluate the performances of composite board as affected by different particle size of $E$. guineensis fronds.

The $E$. guineensis frond particles were microwave pre-treated prior to mixing with $10 \%$ urea formaldehyde. The physical and mechanical properties of all composite board were compiled and investigated. In addition, the cross section and surface morphologies of fabricated boards were characterized to determine the bonding quality of the experimental composite boards as a function of particle sizes selection.

\section{MATERIALS AND METHODS}

Fresh E. guineensis fronds were supplied by local oil palm plantation. E. guineensis fronds were chipped, and oven dried to 6-8\% moisture contents with a heating temperature of $100^{\circ} \mathrm{C}$. The oven dried E. guineensis frond chips were then further reduced into particulate shape by using a crusher machine.

The crushed E. guineensis frond particles were then distributed on the sieve mesh of $2.0 \mathrm{~mm}$, $1.18 \mathrm{~mm}$ and $0.60 \mathrm{~mm}$, respectively via vibrational sieving machine. Only particles that retained on the $1.18 \mathrm{~mm}$ and $0.60 \mathrm{~mm}$ sieve meshes were selected to be used in the fabrication of composite board. A one minute microwave pre-treatment at 700 watt were applied on raw El guine.nsis frond particles before mixing with $10 \%$ low formaldehyde emission urea formaldehyde (UF) resins. The composite boards were made on a laboratory scale by standard techniques and controlled conditions. E. guineensis frond particles were weighed and placed into a steel mould with dimension of $(20 \times 20 \times 0.50) \pm 0.02 \mathrm{~cm}$ with targeted densities of $0.8 \mathrm{~g} / \mathrm{cm}^{3}$. The mats were compressed by using hot press machine under the pressure of $7 \mathrm{MPa}$ with platen temperature of $160{ }^{\circ} \mathrm{C}$ for 20 minutes.

The pressed composite boards were then left cooled followed by cutting of test specimens based on Japanese Industrial Standards (JIS A5908:2003) [15]. The test specimens were then conditioned in a conditioning chamber at temperature of $20 \pm 2{ }^{\circ} \mathrm{C}$ and relative humidity of $65 \pm 5 \%$ for seven days.

Three replicated samples of each board were prepared to be tested for physical and mechanical properties and the average data were analyzed.

\section{Particle Size Characterization}

A random of 100 E. guineensis frond particles retained at $1.18 \mathrm{~mm}$ and $0.60 \mathrm{~mm}$ sieve mesh, respectively were selected from each mesh to be cross- checked by using HIROX KH-8700 3D digital microscope.

\section{Physical Testing}

The physical properties of E. guineensis frond composite boards were tested by performing water absorption (WA) and thickness swelling (TS) tests. For each test, specimens with dimension of $5 \mathrm{~cm} \times 5 \mathrm{~cm}$ were prepared. All specimens were soaked in distilled water for 24 hours. The results after 24 hours immersion were measured and recorded for both WA and TS, respectively.

\section{Mechanical Testing}

Internal bonding (IB) test and modulus of rupture (MOR) were performed to evaluate the mechanical properties of E. guineensis frond composite board. The Hegewald and Peschke Testing Machine with load capacity of $10 \mathrm{kN}$ was employed. The testing speeds applied for IB test and MOR test were $2 \mathrm{~mm} / \mathrm{min}$ and $10 \mathrm{~mm} / \mathrm{min}$, respectively.

\section{Morphological Characterization}

A scanning electron microscopy (SEM) model JEOL JCM-6000 was used to analyse the effect of different particle sizes on the internal and surface textures of composite board. Each specimen with dimensions of $0.5 \mathrm{~cm} \times 0.5 \mathrm{~cm}$ was prepared from the failure section of IB test specimens. The specimens were gold coated by an ion sputter coater (JEOL JEC-3000FC Auto Fine Coater) before micrographs of the specimens are taken under high resolution. 


\section{RESULTS AND DISCUSSION}

\section{Particle Size Characterization}

The sorting process of E. guineensis frond particles is very important to get the optimal size of particles for fabrication of composite boards with excellent physical and mechanical properties [16]. Vibrational sieving method was employed to distribute a large number of particles into chosen mesh sizes $(0.60 \mathrm{~mm}$ and $1.18 \mathrm{~mm})$. Later, the optical microscopic method was used to characterize or cross-check the specific shapes and size (length and width) of the particles. Combination of both methods are very important as not only a large number of particles can be obtained but the specific size range of particles that retained on each sieve can be characterized.
Table 1 illustrate the result of the percentage of $E$. guineensis particles retained at each sieve mesh, respectively. From the table, it shows that from 100 random samples taken from $0.6 \mathrm{~mm}$ and $1.18 \mathrm{~mm}$ mesh respectively, most of the samples $(55-57 \%)$ having sizes larger than the sieve mesh. Only $5-10 \%$ of the samples with size range below than $0.6 \mathrm{~mm}$ and 1.18 $\mathrm{mm}$ mesh retained on each sieve. This was due to the excessive overlapping of particles during sieving which clogged the pathway for small particles to pass through the mesh openings. Besides, the length of particles which are longer than the sieve openings also prevent the particles to pass through the mesh since the particles are continuously in horizontal positions while sieving.

Table 1: Percentage of Elaeis guineensis Frond Particles Retained at Each Sieve Mesh and Diameter Measured

\begin{tabular}{ccc}
\hline Sieve mesh & Size Range $(\mathbf{m m})$ & Percentage $(\%)$ \\
\hline \multirow{2}{*}{$0.60 \mathrm{~mm}$} & $0.20-0.40$ & 5 \\
& $0.41-0.60$ & 10 \\
& $0.61-0.80$ & 28 \\
& 0.81 and above & 57 \\
\hline \multirow{2}{*}{$1.18 \mathrm{~mm}$} & $0.40-0.60$ & 6 \\
& $0.61-0.80$ & 9 \\
& $0.81-1.00$ & 30 \\
& 1.10 and above & 55 \\
\hline
\end{tabular}

\section{Physical Properties}

Physical properties of a material are defined as the changes that can be observed or measured without disturbing the composition in the material such as thickness swelling (TS) and water absorption (WA). Figure 1 indicates the thickness swelling (TS) results of E. guineensis fronds composite board manufactured with particle size of $0.60 \mathrm{~mm}$ and $1.18 \mathrm{~mm}$, respectively. It is shown that the composite board with coarse $(1.18 \mathrm{~mm})$ particles has TS value of $29.87 \%$, whereas the composite board with fine $(0.60 \mathrm{~mm})$ particles has TS value of $29.02 \%$. The $1.18 \mathrm{~mm}$ particle sized composite board showed slightly higher TS value as compared to composite board with finer particles due to poor interlocking between particles that allow more water to pass through the voids in composite board, hence causes the board to swell easily.

These results can be supported by previous research of Astari, Prasetiyo [17], whereby the outcome of the research work showed better TS on the composite boards fabricated from finer $(2.0 \mathrm{~mm})$ particles as compared to composite boards fabricated from coarse $(3.36 \mathrm{~mm})$ particles.

Similar findings from present and previous study indicate that particle sizes of raw material are significant towards the TS of E. guineensis fronds composite board, especially after experienced water immersion for certain period of time.

Figure 2 shows the comparison of water absorption (WA) results between E. guineensis fronds composite board manufactured from particle size of $0.60 \mathrm{~mm}$ and $1.18 \mathrm{~mm}$, respectively. The graph of results showed that $0.60 \mathrm{~mm}$ particle sized composite board has $4.88 \%$ higher WA value than $1.18 \mathrm{~mm}$ particle sized composite board, which having WA result of $131.04 \%$. 


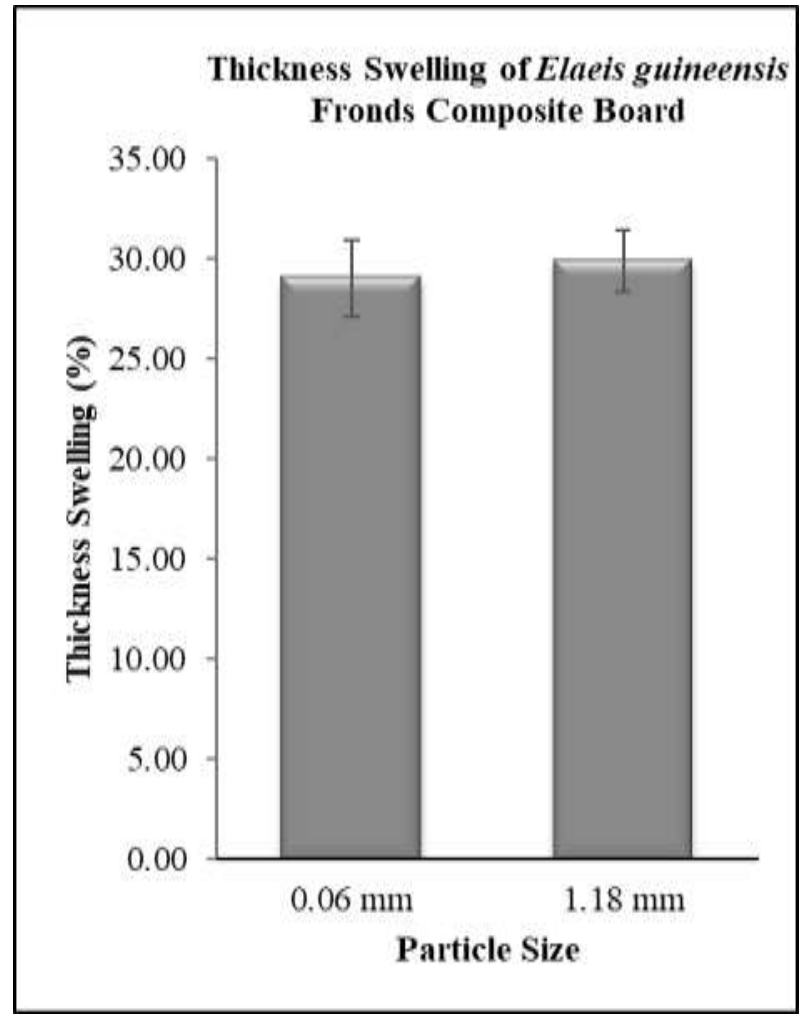

Figure 1: Thickness Swelling of E. guineensis Fronds Composite Board after 24 hours of Immersion

Although fine particles have higher chances to fill the voids in composite board, the high water uptake was resulted from the poor arrangement and compactness of E. guineensis frond particles at a certain part of composite board. Consequently, the conditions had affected the structure and spaces between particles that also contributed to better flowing and absorption of water.

Besides that, poor distribution of adhesive is another factor that leads to efficient water uptake due to changes in composite board's structure when being immersed in water. Particles that were not bonded properly tend to loosen apart from the compressed composite board after experienced long period of immersion [18].

The overall results for physical properties of present E. guineensis fronds composite board which showed relatively high TS and WA showed that E. guineensis fronds composite board is a good water absorbance. This is due to the natural spongy characteristic of $E$. guineensis frond which makes it hydrophilic $\{7\}$.

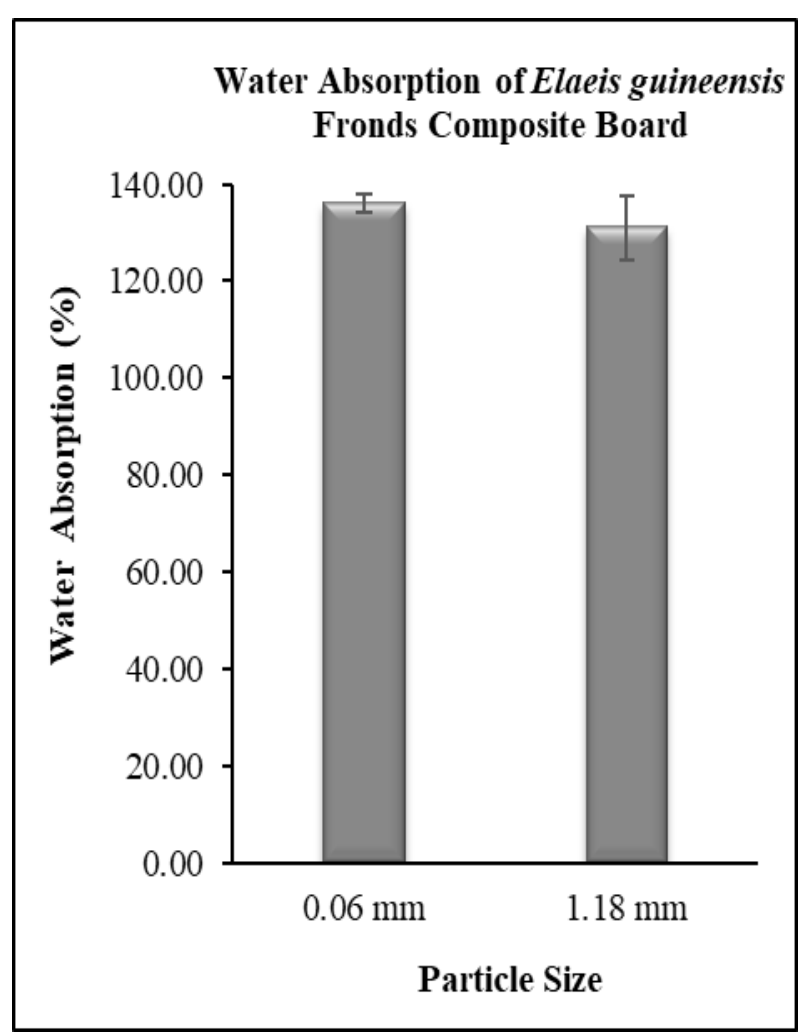

Figure 2: Water Absorption of E. guineensis Fronds Composite Board after 24 hours of Immersion

\section{Mechanical Properties}

Mechanical properties are defined as the strength and resistance to deformation of material either by compressive or tension test. In this research, the study of mechanical properties was focused on the internal bond (IB) strength and modulus of rupture (MOR).

IB strength test was conducted to examine the interfacial bonding strength between $E$. guineensis frond particles in composite board [19]

Figure 3 presented that the IB strength results of E. guineensis fronds composite board fabricated from $0.60 \mathrm{~mm}$ particle size is having slightly higher IB strength compared to $1.18 \mathrm{~mm}$ particle sized composite board. The IB strength result recorded for both composite both is $6.23 \mathrm{~N} / \mathrm{mm}^{2}$ and $6.11 \mathrm{~N} / \mathrm{mm}^{2}$, respectively.

This is because fine particles will have higher tendency to fill the voids among each other [20] during fabrication whereas coarse particles will have difficulties to fit in the voids presence between each other especially when being compacted in a closed mold. 
The same findings were explained by Fu et al. [21] and Chiang et al. [14] whereby internal bonding strength of composite reduced due to poor surface area of bonding between coarse particles. In addition, the formation of void spaces consequently caused failure when the test piece is pulled [14, 21]. To add on, it is shown that all IB results obtained through the present study exceed the minimum requirement of $0.15 \mathrm{~N} / \mathrm{mm}^{2}$ stated in JIS A5908:2003.

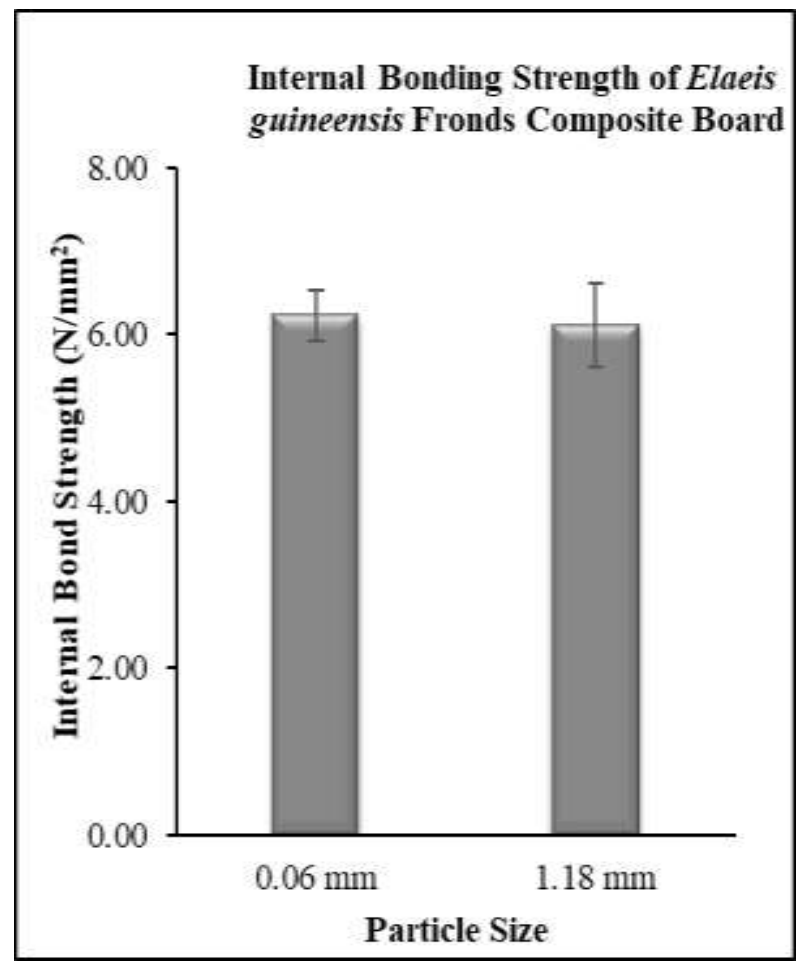

Figure 3: Internal Bonding Streng th of E. guineensis Fronds Composite Board

The purpose of the MOR test is to examine the ability of the test piece to resist the maximum bending force perpendicular to its longitudinal axis [10].

The MOR of E. guineensis fronds composite board manufactured from $0.60 \mathrm{~mm}$ and 1.18 particle size, respectively is shown in Figure 4. From the graph plotted, it is shown that the composite board with coarser $E$. guineensis frond particles has higher MOR (22.37 $\mathrm{N} / \mathrm{mm}^{2}$ ) than composite board manufactured with finer particles $\left(18.58 \mathrm{~N} / \mathrm{mm}^{2}\right)$. This is because of the effect of particle's slenderness ratio (length of the particle divided by its width) and compactness of composite board.

According to Biswas, D. et al. [3], the increase in MOR value is affected by the increase in the slenderness ratio of particles used. Besides that, presence of poor glue also contributed to the outcome of MOR strength. This situation can be seen through the visible distribution of hardens glue on the specimens.

To add on, the influence of E. guineensis frond particle sizes towards MOR of E. guineensis fronds composite board was further affected by the arrangement of the particles in composite board, surface contact between particles and slenderness ratio of particles. Hence, the strength of composite board to withstand the bending force was attributed by the geometry characteristics of $E$. guineensis frond particles used in the manufacturing of composite board. Besides, it is shown that all MOR results obtained through the present study exceed the minimum requirement of 8.0 $\mathrm{N} / \mathrm{mm}^{2}$ stated in JIS A5908:2003 for based particleboard and decorative particleboard classifications.

\section{Modulus of Rupture of Elaeis guineensis Fronds Composite Board}

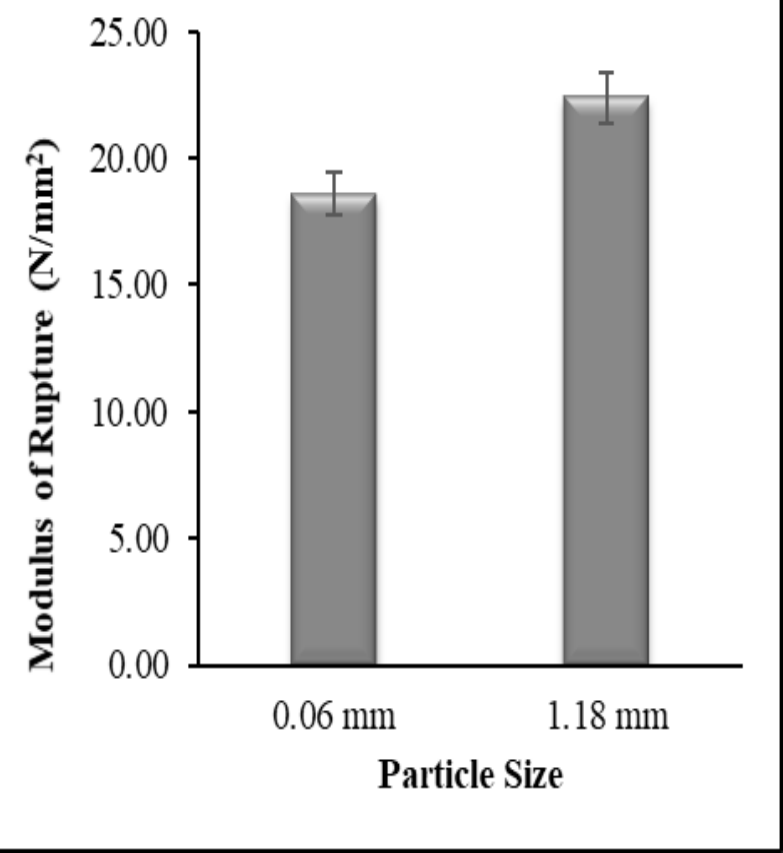

Figure 4: Modulus of Rupture of E. guineensis Fronds Composite Board

\section{Morphological Characterization}

The SEM images of E. guineensis fronds composite board manufactured with $0.60 \mathrm{~mm}$ and $1.18 \mathrm{~mm}$ particle sizes were presented in Figure 5 and Figure 6, respectively. Both composite board samples are having board's density of $0.8 \mathrm{~g} / \mathrm{cm}^{3}$ which were fabricated under hot press temperature and pressure of $160^{\circ} \mathrm{C}$ and 7 $\mathrm{MPa}$, respectively. 
The cross-section morphology of sample in Figure 6(a) showed loosely arranged particles which barely fit in the vacancies between particles as compared to the sample in Figure 5(a) by which the particles were shown to properly fit all the voids.

By observing at the surface morphology of sample in Figure 5(b) and Figure 6(b), it is clearly shown that the arrangement of particles on E. guineensis fronds composite board surface in Figure 5(b) is neatly packed compared to the arrangement of particles on composite board's surface in Figure 6(b), this is because finer $E$. guineensis fronds particles can fit into void spaces between particles easily compared to coarse particles.

The effect of particle sizes on the E. guineensis fronds composite board does play an important part in affecting the texture and interlocking behavior between particles in the fabrication of the board.

From morphological characterization of $E$. guineensis fronds composite board shown in Figure 5 and Figure 6, it was clearly seen that the coarse particles experienced difficulty to fill the voids between particles compared to finer particles especially during manufacturing of board's in closed mold [20].

Previous research discovered that the poor mechanical performance of composite boards is due to the poor surface interlocking between particles which lead to the presence of void spaces [14]. Besides that, the particle size contributes indirectly to the arrangement of particles during composite board manufacturing. Therefore, poor particles arrangement is another factor that lead to the failure in the physical and mechanical properties of the composite board [13].

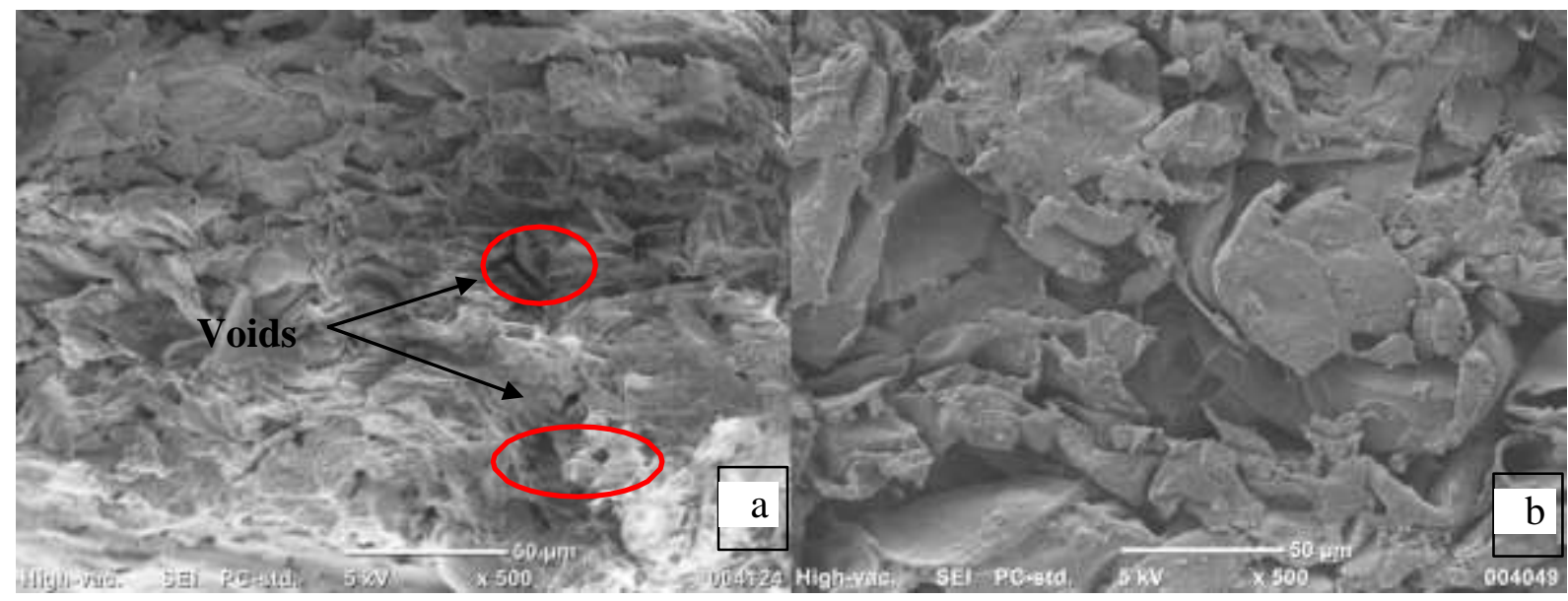

Figure 5: Cross Section (a) and Surface (b) Morphologies of E. guineensis Fronds Composite Board. Fabricated with Particles Retained on $0.60 \mathrm{~mm}$ Sieve Mesh at $\times 500$ Magnification.

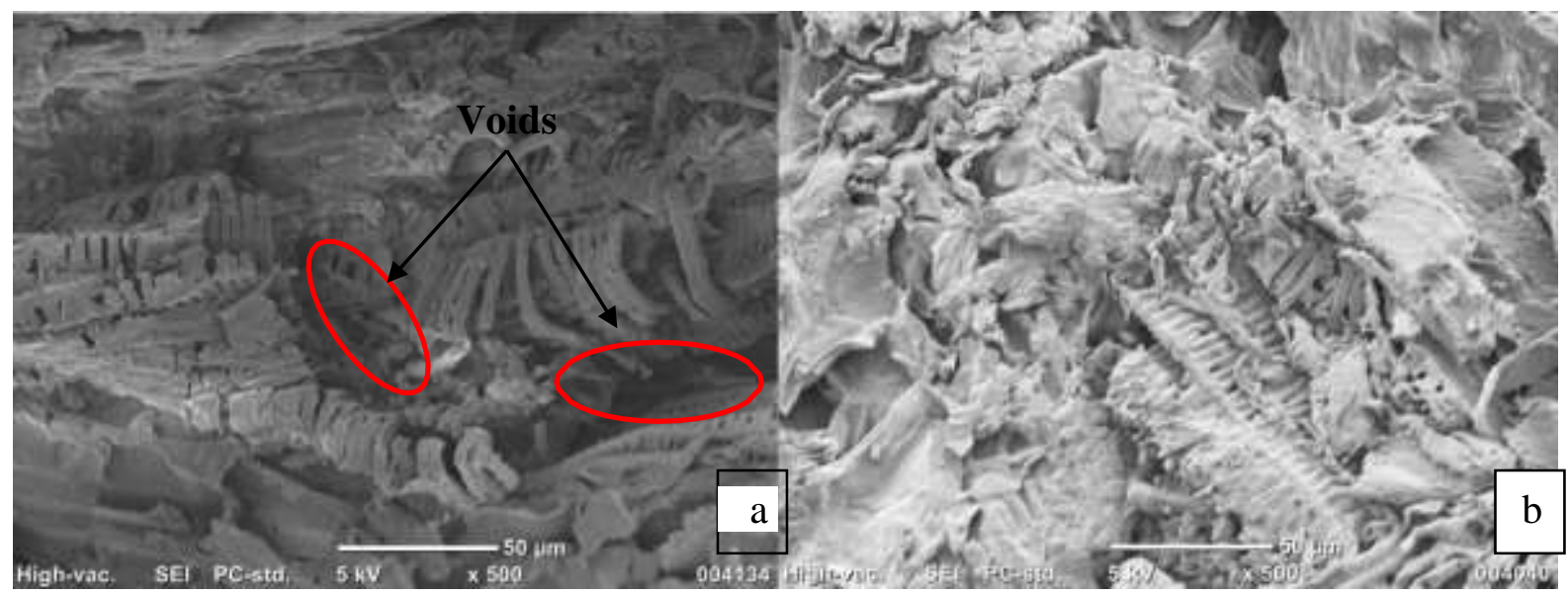

Figure 6: Cross Section (a) and Surface (b) Morphologies of E. guineensis Fronds Composite Board Fabricated with Particles Retained on $1.18 \mathrm{~mm}$ Sieve Mesh at $\times 500$ Magnification. 


\section{CONCLUSION}

The effect of particle sizes does influence the performance of microwave pre-treated $E$. guineensis fronds composite board. Overall results indicated that the strength of composite boards met the requirement of Japanese Industrial Standard of Particleboard (JIS A5908:2003). However, the hydrophilic characteristic of E. guineensis fronds composite board detected from overall TS and WA results disclosed that the composite board is more suitable to be used in a dry conditioned environment. The performance of composite board's TS and WA can be improved by mixing E. guineensis frond particles with hydrophobic polymer substances or wax as finisher. The morphology of E. guineensis fronds composite board revealed that the interlocking and arrangement between particles in composite board is closely related to the selection of particle sizes.

\section{ACKNOWLEDGMENT}

This research was supported by University College of Technology Sarawak (UCTS), Hexzachem Sarawak Sdn. Bhd and Zumida Oil Palm Plantation Sibu. A great appreciation credited to aforementioned organizations for providing research facilities and materials throughout the research period.

\section{REFERENCES}

[1] Okuda, N., \& Sato, M. (2004). Manufacture and mechanical properties of binderless boards from kenaf core. J Wood Sci, 50, 53-61.

[2] Sato, M., Ando, M., Sugimoto, T., \& Hashim, R. (2010). Possibility of utilization of oil palm as a raw material for wood-based material. Paper presented at the World Conference on Timber Engineering, Riva del Garda, Italy.

[3] Biswas, D., Bose, S. K., \& Hossain, M. M. (2011). Physical and mechanical properties of urea formaldehyde-bonded particleboard made from bamboo waste. International Journal of Adhesion \& Adhesives, 31, 84-87.

[4] Kelly-Yong, T. L., Lee, K. T., Mohamed, A. R., \& Bhatia, S. (2007). Potential of hydrogen from oil palm biomass as a source of renewable energy worldwide. Energy Policy, 35, 5692-5701.
[5] Awalludin, M. F., Sulaiman, O., Hashim, R., Aidawati, W. N., \& Nadhari, W. (2015). An overview of the oil palm industry in Malaysia and its waste utilization through thermochemical conversion, specifically via liquefaction. Renewable and Sustainable Energy Reviews, 50, 1469-1484.

[6] Yusoff, S. (2006). Renewable energy from palm oil Innovation on effective utilization of waste. Journal of Cleaner Production, 14 (1), 87-93.

[7] Nordin, N. A., Sulaiman, O., Hashim, R., \& Kassim, M. H. M. (2017). Oil palm frond waste for the production of cellulose nanocrystals. Journal of Physical Science, 28 (2), 115-126.

[8] F., W. A., \& Najmuldeen, G. F. (2015). One layer experimental particleboard from oil palm frond particles and empty fruit bunch fibers. International Journal of Engineering Research \& Technology 4 (1), 199-202.

[9] Laemsak, N., \& Okuma, M. (2000). Development of boards made from oil palm frond II: Properties of binderless boards from steam-exploded fibers of oil palm frond. Japan Wood Science, 46, 322-326.

[10] Green, D. W., Winandy, J. E., \& Kretschmann, D.E D.E. (2010). Mechanical properties of wood. Wood handbook Wood as an engineering material. Madison, Wisconsin: U. S. Department of Agriculture, Forest Service, Forest Products Laboratory.

[11] Aguilar-Reynosa, A., Romani, A., Rodríguez- Jasso, R. M., Aguilar, C. N., Garrote, G., \& Ruiz, H. A. (2017). Microwave heating processing as alternative of pretreatment in second-generation biorefinery: An overview. Energy Conversion and Management, 136, 50- 65.

[12] Tajuddin, M., Ahmad, Z., \& Ismail, H. (2016). A review of natural fibers and processing operations for the production of binderless boards. BioResources, 11(2), 5600-5617.

[13] Hashim, R., Saari, N., Sulaiman, O., Sugimoto, T., Hiziroglu, S., Sato, M., \& Tanaka, R. (2010). Effect of particle geometry on the properties of binderless particleboard manufactured from oil palm trunk. Materials and Design, 31, 4251-4257 
[14] Chiang, T. C., Hamdan, S., \& Osman, M. S. (2016b). Mechanical strength of sago/urea formaldehyde particleboard affected by the particle size. ResearchGate, 1-8.

[15] Association, J. S. (2003). Japanese Industrial Standard Particleboards (Vol. JIS A 5908 : 2003 Particleboards). Japan: Japanese Standards Association.

[16] Tay, C. C., Hamdan, S., \& Osman, M. S. B. (2016). Properties of sago particleboards resinated with UF and PF resin. Advances in Materials Science and Engineering, 2016, 1- 12.

[17] Astari, L., Prasetiyo, K. W., \& Suryanegara, L. (2018). Properties of particleboard made from wood waste with various size. IOP Conference Series: Earth and Environmental Science 166, 1-7.
[18] Chiang, T. C., Hamdan, S., \& Osman, M. S. (2016a). Effects of density of sago/urea formaldehyde particleboard towards its thermal stability, mechanical and physical properties. Jurnal Teknologi (Sciences \& Engineering), 78(10), 187-197.

[19] Saad, M. J., \& Kamal, I. (2012). Mechanical and physical properties of low density kenaf core particleboards bonded with different resins. Journal of Science and Technology, 4(1), 17-32.

[20] Sackey, E. K., Semple, K. E., Oh, S.-W., \& Smith, G. D. (2008). Improving core bond strength of particleboard through particle size redistribution. Wood and Fiber Science, 40(2), 214-224.

[21] Fu, S.-Y., Feng, X.-Q., Lauke, B., \& Mai, Y.W. (2008). Effects of particle size, particle/ matrix interface adhesion and particle loading on mechanical properties of particulatepolymer composites. Composites Part B: Engineering, 39(6), 933-961. 